\title{
Clinical Characteristics and Comparative Analysis of Covid-19 Patients With or Without HIV Coinfection in Wuhan, China
}

\section{Rongrong Yang}

Wuhan University Zhongnan Hospital

Xien Gui

Wuhan University Zhongnan Hospital

Yongxi Zhang

Wuhan University Zhongnan Hospital

Yong Xiong

Wuhan University Zhongnan Hospital

Shicheng Gao

Wuhan University Zhongnan Hospital

Hengning Ke ( $15729577635 @ 163 . c o m)$

Wuhan University Zhongnan Hospital

\section{Research Article}

Keywords: COVID-19, SARS-CoV-2, AIDS, Viral shedding

Posted Date: June 16th, 2020

DOI: https://doi.org/10.21203/rs.3.rs-34735/v1

License: (c) (i) This work is licensed under a Creative Commons Attribution 4.0 International License. Read Full License 


\section{Abstract}

Background: COVID-19 is a public health emergency that is spreading worldwide and seriously affecting global economy. Information about the impact of HIV co-infection and anti-HIV drugs on the clinical characteristics and prognosis of COVID-19 patients remains limited.

Methods: In this retrospective study, the maximum body temperatures, fever duration, chest computed tomography changes and viral shedding, lymphocyte counts changes and titer of SARS-CoV-2 antibody were compared between COVID-19 patients with and without HIV infection in Zhongnan Hospital of Wuhan University from January 20th to February 14th, 2020.

Results: Compared with 50 control COVID-19 patients, the two COVID-19/HIV co-infection patients had higher maximum body temperatures $\left(40.2^{\circ} \mathrm{C}\right.$ and $40.3^{\circ} \mathrm{C}$ vs $\left.38.2^{\circ} \mathrm{C}\right)$, longer fever duration $(11$ days and 15 days vs 7 days), longer time of lung recovery (20 days and 24 days vs 14 days), shorter duration of viral shedding after the onset of symptoms( 6 days and 4 days vs 10 days). Compared with three COVID-19 infection colleagues who had exposure history with the same COVID-19 patient, the third COVID-19/HIV coinfection patient had the same duration of viral shedding after exposure(29 days vs 29 days), lower titer of SARS-CoV-2 IgG(negative vs positive for all).

Conclusion: For patients co-infected with HIV, the clinical manifestations of SARS-CoV-2 infection were diverse. The ability of those COVID-19/HIV co-infection patients with severe immunodeficiency to produce SARS-CoV-2 antibodies were weakened. The small sample in this study implied that the effects of anti-HIV drugs in prevention and treatment of COVID-19 appears to be limited.

\section{Introduction}

COVID-19 is a public health emergency that is spreading worldwide and seriously affecting global economy[1-5]. There are currently no drugs available to inhibit SARS-CoV-2 replication. Due to the limited experience of combination of lopinavir, ritonavir and interferon beta (LPV/RTV-IFN $\beta$ ) in the treatment of MERS[6, 7], the question of whether or not anti-HIV drugs can play a role in the the prevention and treatment of COVID-19 has been drawn attention by public[8]. Therefore, in this background, limited information on COVID-19/HIV co-infection patients were showed and analyzed in this study, in order to provide clinical clues for future prospective studies.

\section{Methods}

\section{Study Population}

All consecutive patients with confirmed COVID-19 admitted to Zhongnan Hospital of Wuhan University from January 20th to February 14th were enrolled. Written or oral informed consent was obtained from patients. This retrospective study was approved by the ethics committee of Zhongnan Hospital of Wuhan University (No. 2020011). 


\section{Real-time Reverse Transcription Polymerase Chain Reaction Assay For Sars-cov-2}

COVID-19 was confirmed by detecting SARS-CoV-2 RNA in throat swab samples using a virus nucleic acid detection kit according to the manufacturer's protocol (Shanghai BioGerm Medical Biotechnology Co.,Ltd). Briefly, the RT-PCR assay for SARS-CoV-2 amplifies simultaneously two target genes: open reading frame $1 \mathrm{ab}$ (ORF1ab) and the ORF for the nucleocapsid protein (N). Target 1 (ORF1ab): forward primer CCCTGTGGGTTTTACACTTAA; reverse primer ACGATTGTGCATCAGCTGA; probe 5'VICCCGTCTGCGGTATGTGGAAAGGTTATGG-BHQ1-3'. Target 2 (N): forward primer GGGGAACTTCTCCTGCTAGAAT; reverse primer CAGACATTTTGCTCTCAAGCTG; probe 5'-FAMTTGCTGCTGCTTGACAGATT-TAMRA-3'. Positive (pseudovirus with a fragment of ORF1ab and N) and negative (pseudovirus with a standard fragment) quality control samples were tested simultaneously. A cycle threshold (Ct) value of less than 37 was defined a positive test, while a $\mathrm{Ct}$ value of more than 40 was defined as a negative test. For the cases with an intermediate $\mathrm{Ct}$ value (37-40), a second sample was tested and weakly positive was defined as a recurrence of $\mathrm{Ct}$ value of 37-40. The diagnostic criteria were based on the recommendation from the National Institute for Viral Disease Control and Prevention (China) [9].

\section{Control Patients Selection}

In this study, the first two COVID-19/HIV co-infection patients had typical clinical symptoms of SARS-CoV-2 infection and imaging manifestations of viral pneumonia. Those COVID-19 patients without HIV infection, who were matched in age and gender, hospitalized in the same period, had similar symptoms and imaging manifestations, and received the same comprehensive treatment measures, were selected as control patients. The third COVID-19/HIV co-infection patient was screened for SARS-CoV-2 at a clinic for AIDSrelated illness, and later confirmed as an asymptomatic COVID-19 patient. He and his three colleagues had exposure history with the same COVID-19 patient, and the three colleagues were selected as control population of the third COVID-19/HIV co-infection patient.

\section{Data Collection}

The following information, such as age, gender, COVID-19-related exposure history, symptoms, signs, severity assessment on admission, laboratory findings and chest CT or X-ray findings were collected. The data were reviewed by a trained team of physicians.

\section{Result}

\section{Baseline of COVID-19 patients with and without HIV infection}


For the two COVID-19 patients with HIV infection, past medical history showed that they were confirmed with HIV infection and received combination antiretroviral therapy for 96 and 75 months, respectively. The antiretroviral regimen were Zidovudine/Lamivudine/Nevirapine and

Tenofovirdisoproxil/Lamivudine/Efavirenz, respectively. The latest CD4 ${ }^{+} \mathrm{T}$ lymphocyte counts were 420 cells/ul and 550 cells/ul. During the hospitalization, ART drugs against HIV were still used.

The 50 cases of COVID-19 patients without HIV infection were hospitalized at the same period, and the median $\mathrm{CD} 4^{+} \mathrm{T}$ lymphocyte count was 638 cells/ul. Whether or not infected with HIV, all the 52 COVID-19 patients were male. None of them reported exposure associated with the Huanan Seafood Wholesale Market or had close contaction with fever patients. Typical viral pneumonia was observed for all patients through chest computed tomography(CT) showing multiple patchy shadows in both lungs, and nasopharyngeal and throat swab specimens collected for SARS-CoV-2 detection were positive. As treatment for COVID-19, all of them received supplement oxygen through a face mask, oseltamivir as antiviral therapy, and antibacterial therapy to prevent secondary infection. The data were shown in Table 1.

Table 1

Baseline of two COVID-19 patients with HIV and fifty COVID-19 patients without HIV infection

\begin{tabular}{|c|c|c|c|}
\hline & \multicolumn{2}{|l|}{ With HIV infection } & \multirow{2}{*}{$\begin{array}{l}\text { Without HIV infection } \\
\text { Patients 3-52 }\end{array}$} \\
\hline & Patient 1 & Patient 2 & \\
\hline $\begin{array}{l}\text { Age(years)/Median } \\
\text { age(years, range) }\end{array}$ & 31 & 60 & $49(31-60)$ \\
\hline Gender & Male & Male & Male \\
\hline $\begin{array}{l}\text { SARS-CoV-2 } \\
\text { exposure history }\end{array}$ & Undefined & Undefined & Undefined \\
\hline Latest/Average CD4+ & 420 & 550 & 638 \\
\hline \multicolumn{4}{|l|}{$\begin{array}{l}\text { T lymphocyte } \\
\text { counts }(/ \mathrm{ul})\end{array}$} \\
\hline Fever & Yes & Yes & Yes \\
\hline $\begin{array}{l}\text { Chest computed } \\
\text { tomography }\end{array}$ & $\begin{array}{l}\text { Multiple patchy } \\
\text { shadows in both lungs }\end{array}$ & $\begin{array}{l}\text { Multiple patchy } \\
\text { shadows in both lungs }\end{array}$ & $\begin{array}{l}\text { Multiple patchy } \\
\text { shadows in both } \\
\text { lungs }\end{array}$ \\
\hline ART regimens & AZT/3TC/NVP & TDF/3TC/EFV & - \\
\hline $\begin{array}{l}\text { ART } \\
\text { duration(months) }\end{array}$ & 96 & 75 & - \\
\hline Oxygen therapy & Yes & Yes & Yes \\
\hline Oseltamivir & Yes & Yes & Yes \\
\hline Antibacterial therapy & Yes & Yes & Yes \\
\hline
\end{tabular}




\section{Comparative of maximum body temperatures and duration of fever between COVID-19 patients with and without HIV infection}

The maximum body temperatures of the two COVID-19 patients with HIV infection were $40.2^{\circ} \mathrm{C}$ and $40.3^{\circ} \mathrm{C}$, respectively, which were higher than those COVID-19 patients without HIV infection(the median value was $38.2^{\circ} \mathrm{C}$ ). The fever duration of the two COVID-19 patients with HIV infection were 11 days and 15 days, which were longer than control COVID-19 patients (the median fever duration was 7 days). These data were shown in Fig. 1.

\section{Comparative of chest computed tomography changes and viral shedding between COVID-19 patients with and without HIV infection}

The point of worst imaging features occurrence time in two COVID-19 patients with HIV were the 11th and 15th day, respectively, whereas the control patients (COVID-19 patients without HIV) was the 8th day(IQR: 5th -11th day). Fortunately, on the 20th and 24th day, respectively, lung lesions of the two COVID-19 patients with HIV showed by chest CT began to shrink or absorb, while the control patients began to improve on the 14th day. It is interesting that, on the 6th and 4th day, nasopharyngeal and throat swab specimens were tested negative for SARS-CoV-2, whereas the control patients were tested negative on the 10th day. These data were shown in Fig. 2.

\section{The epidemiological exposure history, detection results and treatment of an asymptomatic SARS-CoV-2 infection patient with AIDS}

The patient was a 29 years old men. He was admitted to hospital for regular chemotherapy for Kaposi's sarcoma on February 12, 2020. The patient had no fever, no dry non-productive cough, no fatigue and no dyspnoea. Past medical history showed that he was confirmed with HIV infection and began to receive mixture antiretroviral drugs (Elvitegravir, Cobicistat, Emtricitabine and Tenofovir Alafenamide Fumarate) against HIV on December 23, 2019. Lymphopenia was showed by blood routine test, but chest CT scans didn't show bilateral ground-glass opacities. On February 14, the patient is ready for discharge because the second chemotherapy for Kaposi's sarcoma finished. Considering the outbreak of COVID-19 in Wuhan, nasopharyngeal and throat swab tested for SARS-CoV-2 were performed as routine for patients discharged from the infectious diseases department. It was not until then that the positive SARS-CoV-2 nucleic acid test was found. By further inquiring about the epidemiological exposure history, the patient recalled that the company organized an annual dinner on January 16, 2020. Around January 20, three colleagues were successively diagnosed with COVID-19 due to fever. During the following isolation period, the patient still did not have any symptoms or signs related to COVID-19. Based on the epidemiological exposure history and etiological results, the patient was confirmed as SARS-CoV-2 asymptomatic infection. The patient was isolated and provided with traditional Chinese medicine decoction treatment. During the isolation period, still no symptoms related to COVID-19 occurred. On February 21 and 22, nasopharyngeal and throat swab specimens tested for SARS-CoV-2 were both negative. During the follow-up monitoring from February 21 to May 17, the patient's viral nucleic acid test for SARS-CoV-2 remained negative. All the data were shown in Fig. 3. 
Comparison of the epidemiological and clinical characteristics of SARS-CoV-2 infection patients who were exposed to the same infectious source

In this study, the third COVID-19/HIV co-infection patient and his three colleagues of the same age and gender had same exposure history. The third COVID-19/HIV co-infection patient was asymptomatic throughout the whole course, while his three colleagues all developed fever and other symptoms after 4-6 days of latent infections. The duration of viral shedding were similar between SARS-CoV-2 infection patients with and without HIV. At 6-8 weeks after exposure, SARS-CoV-2 IgG was negative in the third COVID-19/HIV co-infection patient, while his three colleagues were all positive. In addition, by monitoring the changes of lymphocyte counts during the course of SARS-CoV-2 infection for 6 weeks, we found the lymphocyte count of the asymptomatic SARS-CoV-2 infection patient with HIV persistently reduced, while lymphocyte counts of his colleagues remained normal or decreased for 4 weeks, but returned to normal level at 4-6 weeks of illness. The data were shown in Table 2. 
Table 2

The Epidemiological and clinical characteristics of asymptomatic SARS-CoV-2 infection patient with AIDS and his three colleagues who were exposed to the same SARS-CoV-2 source

\begin{tabular}{|c|c|c|c|c|c|}
\hline & SARS-CoV-2 & His colleagues w & hout HIV infection & & \\
\hline & $\mathrm{pe}$ & Colleague 1 & Colleague 2 & Colleague 3 & \\
\hline Age(years) & 29 & 27 & 29 & 30 & \\
\hline Gender & Male & Male & Male & Male & \\
\hline Symptoms & & & & & \\
\hline Fever & No & Yes & Yes & No & \\
\hline Cough & No & Yes & Yes & Yes & \\
\hline Fatigue & No & Yes & Yes & Yes & \\
\hline Dyspnoea & No & No & Yes & No & \\
\hline $\begin{array}{l}\text { Incubation } \\
\text { period(days) }\end{array}$ & $\begin{array}{l}\text { Indefinite } \\
\text { duration }\end{array}$ & 5 & 6 & 4 & \\
\hline $\begin{array}{l}\text { The first time } \\
\text { of SARS- } \\
\text { CoV-2 } \\
\text { negative by } \\
\text { PCR after } \\
\text { exposure(days) }\end{array}$ & 29 & 29 & 30 & 28 & \\
\hline $\begin{array}{l}6-8 \text { weeks } \\
\text { after exposure }\end{array}$ & & & & & $\begin{array}{l}\text { Normal } \\
\text { range }\end{array}$ \\
\hline 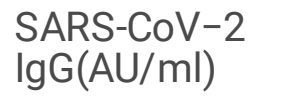 & 1.036(Negative) & 75.38(Positive) & 3.019(Positive) & 67.63(Positive) & $<1.1$ \\
\hline $\begin{array}{l}\text { SARS-CoV-2 } \\
\operatorname{lgM}(\mathrm{AU} / \mathrm{ml})\end{array}$ & 0.224 (Negative) & 0.210 (Negative) & 0.365(Negative) & 0.779(Negative) & $<1.1$ \\
\hline $\begin{array}{l}\text { Lymphocyte } \\
\text { count, } \times 10^{9} / \mathrm{L}\end{array}$ & & & & & $\begin{array}{l}\text { Normal } \\
\text { range }\end{array}$ \\
\hline $\begin{array}{l}\text { Within } 2 \text { weeks } \\
\text { of illness }\end{array}$ & 0.43 & 0.59 & 1.0 & 1.37 & $\begin{array}{l}1.1- \\
3.2\end{array}$ \\
\hline $\begin{array}{l}2-4 \text { weeks of } \\
\text { illness }\end{array}$ & 0.98 & 0.62 & 0.39 & 1.34 & $\begin{array}{l}1.1- \\
3.2\end{array}$ \\
\hline $\begin{array}{l}4-6 \text { weeks of } \\
\text { illness }\end{array}$ & 0.70 & 2.3 & 1.12 & 2.23 & $\begin{array}{l}1.1- \\
3.2\end{array}$ \\
\hline
\end{tabular}

\section{Discussion}


Cases of COVID-19/HIV co-infection were not common until now. Although a severe case involving coinfection of SARS-CoV-2 and HIV was reported[10], information about the impact of HIV co-infection and anti-HIV drugs on the clinical characteristics and prognosis of COVID-19 patients remains limited.

- In this study, even if COVID-19 patients co-infected with HIV, they can show clinical and imaging manifestations of typical viral pneumonia[11], or they cannot have any clinical symptoms and imaging manifestations of lung damage, which suggesting that HIV co-infection does not affect the diagnosis and clinical typing of COVID-19.

- Fever is the initial symptoms and primary cause of hospitalization for most COVID-19 patients[12]. The 2 cases of COVID-19/HIV co-infection patients in this study appeared abnormal temperature as high as 40 degrees. Moreover, compared with COVID-19 patients without HIV infection, they had longer duration of fever and longer time of pulmonary imaging recovery, but their prognosis were the same as those COVID-19 patients without HIV infection. The limited data disclosure that, even for immunodeficient population, such as COVID-19/HIV co-infection patients, they still have the opportunity to regain their health after comprehensive treatment.

- In addition to clinical symptoms such as fever, in terms of blood test indicators, lymphocytopenia is one of the characteristics of advanced stage of AIDS after HIV infection. Meanwhile it is common among COVID-19 patients[13]. As for the third COVID-19/HIV co-infection patient in this study, two out of his three colleagues appeared lymphocytopenia, but their lymphocyte counts returned to normal in later stage of COVID-19, whereas he is persistently lymphocytopenia throughout the observation period. We can preliminarily speculate that the lymphocytopenia associated with SARS-CoV-2 infection can return to normal along with the improvement of the disease. This is different from the lymphocytopenia caused by chronic HIV infection which requires ART for a long time to return to normal.

- In generally, it is difficult to obtain an effective treatment options during a short time of the outbreak of a new emerging viral diseases. As such, treatments designed and approved for other diseases are administered to patients with emerging viral syndromes empirically based on limited clinical or laboratory data. By referring the limited experience on Middle East respiratory syndrome coronavirus (MERS-CoV) treatment[6], a combination of lopinavir, ritonavir and interferon beta (LPV/RTV-IFN $\beta$ ) is speculated to be valid for severe COVID-19 patients. This has led to speculation about the use of antiHIV drugs to treat COVID-19. For the 2 cases of COVID-19/HIV co-infection patients in this study, even the duration of SARS-CoV-2 shedding from the onset of symptoms was shorter than those COVID-19 patients without HIV infection, we cannot assume that anti-HIV drugs can shorten duration of SARSCoV-2 shedding, as we cannot confirm or exclude the same incubation period between the two groups. The third asymptomatic COVID-19/HIV co-infection patient in this study had same exposure history as the other three colleagues. Even though the former was taking anti-HIV drugs, his duration of SARSCoV-2 shedding from exposure was similar to his three colleagues. Therefore, we speculated that the anti-HIV drugs taken by the COVID-19/HIV co-infection patient in this cluster failed to shorten the duration of SARS-CoV-2 shedding. In addition, all COVID-19/HIV co-infection patients in this study acquired SARS-CoV-2 infection during ART process, suggesting that anti-HIV drugs have limited effect on the prevention of SARS-CoV-2 infection. 
Lymphocytes can play an important role in the maintenance of immune system function[14]. CD $4^{+} \mathrm{T}$ lymphocyte cells of the third COVID-19/HIV co-infection patient in this study was only 21 cells/ul, which indicating an extreme immunodepletion state. His level of SARS-CoV-2 IgG was too low to be positive, whereas all of his three colleagues were positive 6-8 weeks after exposure. In view of the previous reports about hepatitis B vaccination in HIV-infected patients, it was found that the lower the CD4 ${ }^{+} \mathrm{T}$ lymphocyte count, the lower proportion of patients to acquire protective HBsAb. Therefore, as for those HIV-infected patients with severe immune deficiency, we speculated that their ability to produce SARS-CoV-2 antibodies could also be weakened. As for this particular population of HIV infection, the impact of CD $4^{+} \mathrm{T}$ lymphocyte counts on SARS-CoV-2 antibodies screening results should be taken into account, when conducting an epidemiological investigation of COVID-19 herd immunity.

There are some limitations in this study. First, as a sudden outbreak of acute infectious disease, the number of COVID-19/HIV co-infections is limit. The situation of COVID-19/HIV co-infection did not receive enough attention in the early stage of COVID-19 outbreak. Future research on the effects of immunodeficiency on COVID-19 can be expanded to follow the clues provided in this study. Second, as no effective and reliable SARS-CoV-2 antibody detection kit had been developed in the early stage of COVID-19 epidemic, the first two COVID-19/HIV co-infection patients and the 50 controlled COVID-19 patients did not receive SARS-CoV2 antibodies testing, which happens to be very important in determining the impact of immune function on SARS-CoV-2 antibodies.

\section{Conclusion}

For patients co-infected with HIV, the clinical manifestations of SARS-CoV-2 infection were diverse. They can be asymptomatic or have a fever of more than 40 degrees, but all of them in this study recovered after symptomatic treatment. However, if the COVID-19/HIV co-infection patients with severe immunodeficiency, their ability to produce SARS-CoV-2 antibodies were weakened. The effects of anti-HIV drugs in prevention and treatment of COVID-19 appears to be limited, but larger sample size of systematic observations are needed to draw conclusions.

\section{Declarations}

\section{Ethical Approval and Consent to participate}

This retrospective study was approved by the ethics committee of Zhongnan Hospital of Wuhan University (No. 2020011). Written or oral informed consent was obtained from patients.

\section{Consent for publication}

Written informed consent for publication can be obtained from all participants.

\section{Availability of data and materials}

All data analyzed during this study are included in this article. 


\section{Competing interests}

The authors declare that they have no competing interests.

\section{Funding}

This project was supported by National Natural Science Foundation of China (Grant No. 81572902).

\section{Authors' contributions}

All authors collected the clinical data. Rongrong Yang, Yongxi Zhang, Yong Xiong and Shicheng Gao drafted the manuscript. Xien Gui and Hengning Ke supervised the final manuscript. All authors were responsible for summarising all data related to this study.

\section{Acknowledgement}

We thank the patients, the nurses and physicians who provided care for the patients, and the investigators at Zhongnan Hospital of Wuhan University.

\section{Authors' information}

Rongrong Yang ${ }^{1}$, Xien Gui ${ }^{1}$, Yongxi Zhang ${ }^{1}$, Yong Xiong ${ }^{1}$, Shicheng Gao ${ }^{1}$, Hengning $\mathrm{Ke}^{2 *}$

1.Department of Infectious Diseases, Zhongnan Hospital, Wuhan University, Wuhan. China

2.The second Clinical College, Medical Department, Wuhan University, Wuhan. China

*Contributed equally. Correspondence authors: Dr Hengning Ke and Dr Shicheng Gao, Donghu Road 169, Wuchang District, Wuhan 430071, Hubei Province, China Email:Hengning Ke(15729577635@163.com) and Shicheng Gao (shichengg@126.com)

Rongrong Yang: yangrr1130@126.com

Xien Gui: znact@126.com

Yongxi Zhang: znact1936@126.com

Yong Xiong: yongxiong64@163.com

\section{References}

1. Huang C, Wang Y, Li X, et al. Clinical features of patients infected with 2019 novel coronavirus in Wuhan, China. LANCET 2020 2020-01-24.

2. Li Q, Guan X, Wu P, Wang X, Zhou L. Early Transmission Dynamics in Wuhan, China, of Novel Coronavirus-Infected Pneumonia. The New England journal of medicine 2020. 
3. Lu H, Stratton CW, Tang YW. Outbreak of Pneumonia of Unknown Etiology in Wuhan China: the Mystery and the Miracle. J MED VIROL 2020 2020-01-16

4. Lillie PJ, Samson A, Li A, et al. Novel coronavirus disease (Covid-19): the first two patients in the UK with person to person transmission. J Infect 2020 2020-02-28.

5. Spina S, Marrazzo F, Migliari M, Stucchi R, Sforza A, Fumagalli R. The response of Milan's Emergency Medical System to the COVID-19 outbreak in Italy. LANCET 2020 2020-02-28.

6. Sheahan TP, Sims AC, Leist SR, et al. Comparative therapeutic efficacy of remdesivir and combination lopinavir, ritonavir, and interferon beta against MERS-CoV. Nature Communications 2020; 11:222. https://doi.org/10.1038/s41467-019-13940-6.

7. Kim UJ, Won EJ, Kee SJ, Jung SI, Jang HC.Combination therapy with lopinavir/ritonavir, ribavirin and interferon-a for Middle East respiratory syndrome. Antivir Ther 2016;21(5):455-9.

8. Cao B, Wang Y, Wen D, et al. A Trial of Lopinavir-Ritonavir in Adults Hospitalized with Severe Covid-19. N Engl J Med 2020 May 7;382(19):1787-99.

9. National Institute for Viral Disease Control and Prevention (China). Specific primers and probes for detection 2019 novel coronavirus. Beijing: National Institute for Viral Disease Control and Prevention (China); 21 Jan 2020.Chinese. Available from: http://ivdc.chinacdc.cn/kyjz/202001/t20200121_211337. html

10. 10. Zhu F, Cao Y, Xu S, et al. Co-infection of SARS-CoV-2 and HIV in a patient in Wuhan city, China. Journal of Medical Virology,2020,92(6):529-30.

11. Huang C, Wang Y, Li X, et al. Clinical features of patients infected with 2019 novel coronavirus in Wuhan, China. Lancet 2020; 395:497-506.

12. Wang D, Hu B, Hu C, et al. Clinical characteristics of 138 hospitalized patients with 2019 novel coronavirus-infected pneumonia in Wuhan, China. 2020; published online Feb 7. DOI:10.1001/jama.2020.1585.

13. Chen N, Zhou M, Dong X, et al. Epidemiological and clinical characteristics of 99 cases of 2019 novel coronavirus pneumonia in Wuhan, China: a descriptive study. 2020; 395: 507-13.

14. Wang F, Nie J, Wang H, et al. Characteristics of Peripheral Lymphocyte Subset Alteration in COVID-19 Pneumonia. The Journal of Infectious Diseases, 2020. DOI: 10.1093/infdis/jiaa150

\section{Figures}




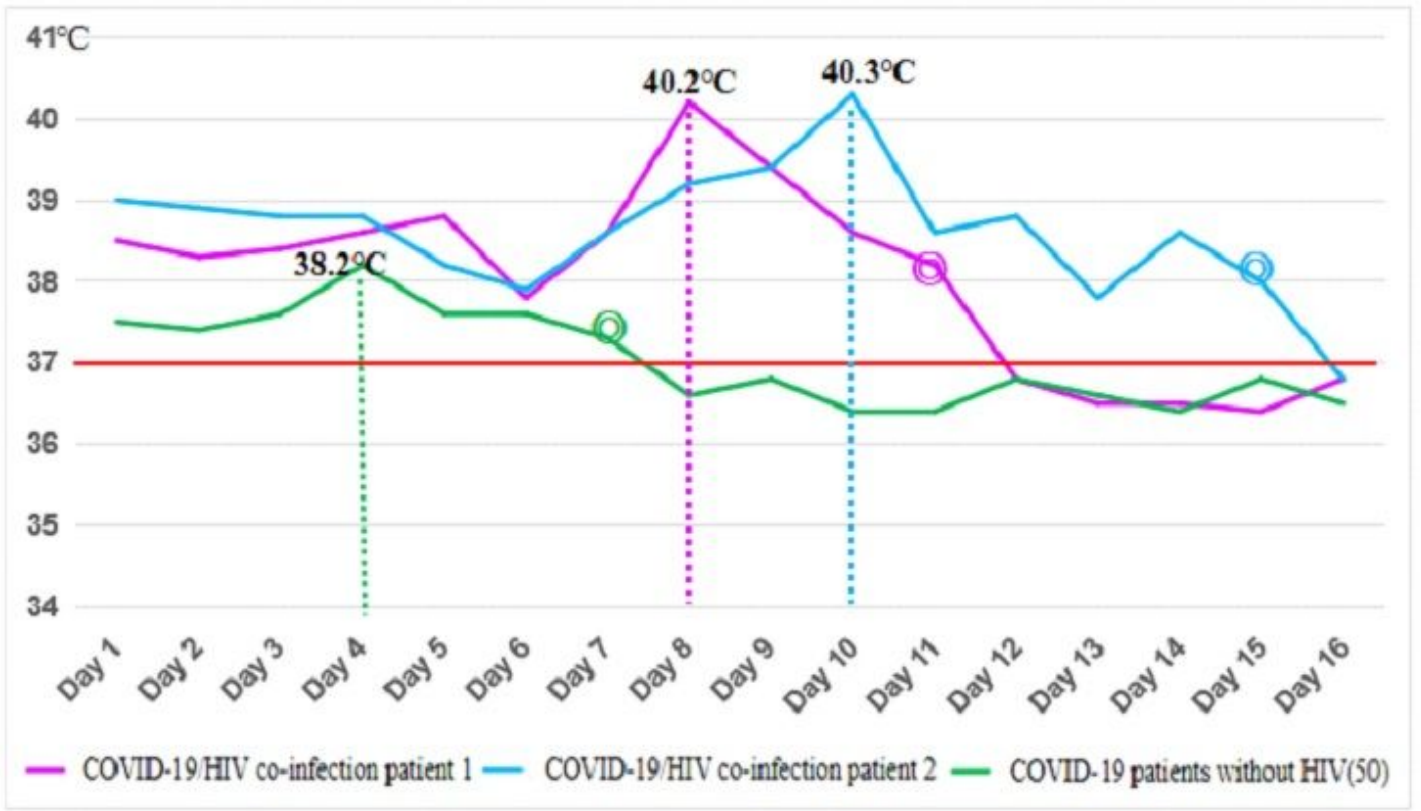

Figure 1. Maximum body temperatures and duration of fever according to day of illness

\section{Figure 1}

The maximum body temperatures of the two COVID-19 patients with HIV infection were $40.2^{\circ} \mathrm{C}$ and $40.3^{\circ} \mathrm{C}$, respectively, but the median value of 50 COVID-19 patients without HIV infection was $38.2^{\circ} \mathrm{C}$. The fever duration of the two COVID-19 patients with HIV infection were 11 days and 15 days, but the median value of 50 COVID-19 patients without HIV infection was 7 days.

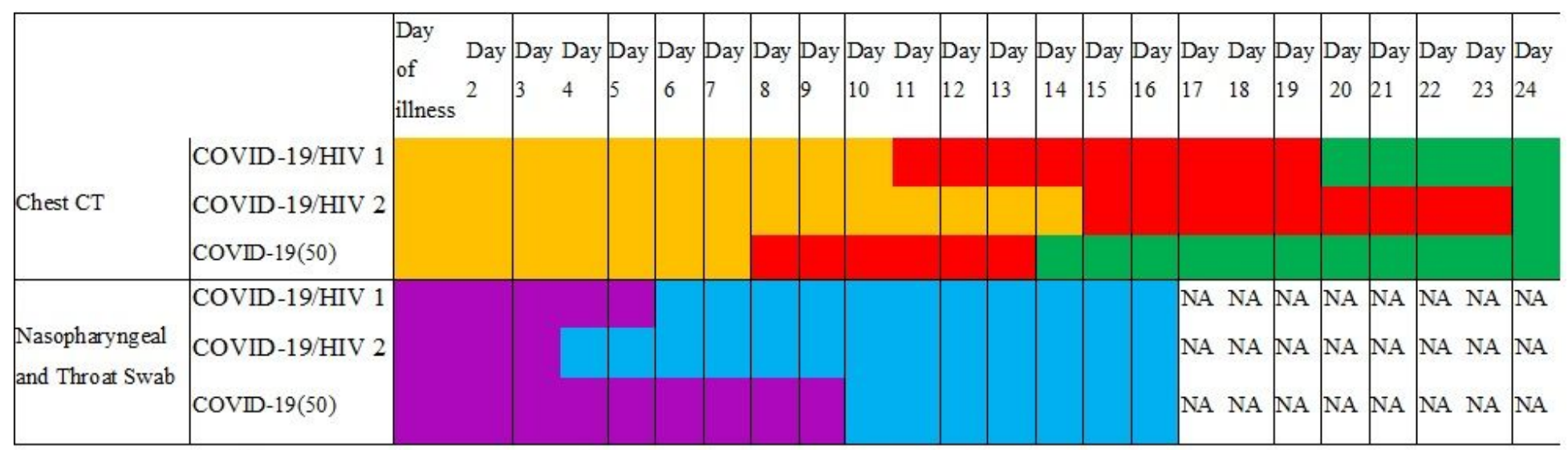

Figure 2. Changes of chest computed tomography and results of real-time reverse-transcriptase-chain-reaction testing for COVID-19

Chest computed tomographic immages show typical manifestations of COVID-19.

Chest computed tomographic immages show the opacities have steadily increased in density over time.

Chest computed tomographic immages show the lung lesions began to improve.

The initial respiratory (nasopharyngeal and throat swab) were positive for COVID-19.

The initial respiratory were negative for COVID-19.

NA: not available.

Figure 2 
Lung lesions of the two COVID-19 patients with HIV showed by chest CT began to shrink or absorb on the 20th and 24th day, respectively, but the median value of 50 COVID-19 patients without HIV infection was 14th day. Nasopharyngeal and throat swab specimens of the two COVID-19 patients with HIV were tested negative for SARS-CoV-2 on the 6th and 4th day, respectively, but the median value of 50 COVID-19 patients without HIV infection was on the 10th day.

\begin{tabular}{|c|c|c|c|c|c|c|c|c|c|}
\hline & \multirow{2}{*}{$\begin{array}{r}2019 \\
\text { Dec.23 }\end{array}$} & \multicolumn{8}{|c|}{2020} \\
\hline & & Jan.16 & $\operatorname{Jan} .20$ & $\operatorname{Jan} .21-23$ & Feb.12-14 & Feb.14-20 & Feb. 20 & Feb. 21 & Feb.21-May.17 \\
\hline $\begin{array}{l}\text { Epidemiological } \\
\text { Exposure } \\
\text { History }\end{array}$ & & $\begin{array}{l}\text { An } \\
\text { annual } \\
\text { dinner }\end{array}$ & $\begin{array}{l}\text { Three } \\
\text { colleagues } \\
\text { were } \\
\text { diagnosed with } \\
\text { COVID-19 } \\
\text { due to fever }\end{array}$ & $\begin{array}{l}\text { Healthcare } \\
\text { workers and } \\
\text { patients had close } \\
\text { contact with this } \\
\text { patient }\end{array}$ & $\begin{array}{l}\text { Healthcare } \\
\text { workers and } \\
\text { patients had close } \\
\text { contact with this } \\
\text { patient }\end{array}$ & & & & \\
\hline Symptoms & & & & & & & & & \\
\hline Fever & No & No & No & No & No & & No & No & No \\
\hline Cough & No & No & No & No & No & & No & No & No \\
\hline Fatigue & No & No & No & No & No & & No & No & No \\
\hline Dyspnoea & No & No & No & No & No & & No & No & No \\
\hline $\begin{array}{l}\text { Blood } \\
\text { Routine Test }\end{array}$ & Lymphopenia & & & Lymphopenia & Lymphopenia & & & Lymphopenia & Lymphopenia \\
\hline $\begin{array}{l}\text { CD4+ T } \\
\text { lymphocyte } \\
\text { counts }\end{array}$ & 21 cells/ul & & & & & & & & \\
\hline Chest CT & & & & Normal & & & Normal & & \\
\hline $\begin{array}{l}\text { Nasopharyngeal } \\
\text { and Throat Swab }\end{array}$ & & & & & Positive & & Negative & Negative & Persistently negative \\
\hline Treatment & $\begin{array}{l}\text { Treat AIDS } \\
\text { with E/C/F/TAF }\end{array}$ & & & $\begin{array}{l}\text { First } \\
\text { chemotherapy } \\
\text { for Kaposi's } \\
\text { sarcoma }\end{array}$ & $\begin{array}{l}\text { Second } \\
\text { chemotherapy } \\
\text { for Kaposi's } \\
\text { sarcoma }\end{array}$ & $\begin{array}{l}\text { Isolation and } \\
\text { traditional } \\
\text { Chinese } \\
\text { medicine }\end{array}$ & & & \\
\hline
\end{tabular}

Figu re 3. T imeline of disease course accord ing to epidemiological exposu re history, detection resu lts and treatment, from Dec 23 , 2019 to

May 17, 2020

\section{Figure 3}

The third COVID-19 patients with HIV and his three colleagues attended the annual dinner on January 16 , 2020. Around January 20, three colleagues were successively diagnosed with COVID-19 due to fever. During the whole isolation period, the third COVID-19 patients with HIV did not have any symptoms or signs related to COVID-19, and the chest CT did not show any signs of viral pneumonia. 